\title{
Relationships of physical activity with metabolic syndrome features and low-grade inflammation in adolescents
}

\author{
C. Platat • A. Wagner • T. Klumpp • B. Schweitzer • \\ C. Simon
}

Received: 8 September 2005 /Accepted: 2 May 2006 /Published online: 22 June 2006

(C) Springer-Verlag 2006

\begin{abstract}
Aims/hypothesis Physical activity has beneficial effects on symptoms of the metabolic syndrome and low-grade inflammation in adults. These associations have rarely been studied in adolescents. Moreover, it has not been established whether they depend on adiposity, fat localisation and adipokines.

Subjects, materials and methods We used cross-sectional data of 640 12-year-old adolescents participating in the Intervention Centred on Adolescents' Physical Activity and Sedentary Behaviour Study (ICAPS). Weight, height, body fat mass and WHR were measured. Metabolic syndrome components, two inflammatory markers (IL-6 and Creactive protein), plasma leptin, adiponectin and soluble TNF- $\alpha$ receptor 1 (sTNF- $\alpha$ R1) were determined. Insulin resistance was estimated by homeostasis model assessment (HOMA) and energy expenditure due to organised leisuretime physical activity (PAE) assessed by questionnaire.

Results The metabolic syndrome was present in $5.8 \%$ of
\end{abstract}

C. Platat $\cdot$ A. Wagner $\cdot$ C. Simon $(\bowtie)$

EA 1801, Epidemiology of Cardiovascular Diseases and Cancers,

Influence of Nutrition and Physical Inactivity,

Louis Pasteur University of Strasbourg, Medical Faculty,

4 rue Kirschleger, F-67085,

Strasbourg, Cedex, France

e-mail: chantal.simon@medecine.u-strasbg.fr

T. Klumpp

Laboratory of Medical Biology,

Strasbourg, France

B. Schweitzer

Academic Inspection of the Department of Bas-Rhin,

Strasbourg, France the adolescents. After adjustment for sex, sexual maturity and socio-economic status, a beneficial relationship between PAE and all metabolic syndrome features was found, but only the associations with HOMA and IL-6 were independent of body fat mass and WHR. Adjusted means from the lowest to the highest tertile of PAE were 1.99, 1.80 and 1.78 for HOMA $(p=0.04)$, and $0.88,0.69$ and $0.70 \mathrm{pg} / \mathrm{ml}$ for IL-6 ( $p=0.02)$. PAE was inversely associated with leptin, independently of body fat mass and WHR $\left(p<10^{-2}\right)$, but not with adiponectin or sTNF- $\alpha$ R1. Further adjustment for adipokines did not change the relationships of PAE with HOMA and IL-6.

Conclusions/interpretation In adolescents, physical activity is inversely related to HOMA and IL-6, independently of adiposity and fat localisation. These relationships are not accounted for by adipokines.

Keywords Adolescents · Exercise · Insulin · Low-grade inflammation $\cdot$ Metabolic syndrome

$\begin{array}{ll}\text { Abbreviations } \\ \text { BF } & \text { body fat mass } \\ \text { CRP } & \text { C-reactive protein } \\ \text { HOMA } & \text { homeostasis model assessment } \\ \text { ICAPS } & \text { Intervention Centred on Adolescents' } \\ & \begin{array}{l}\text { Physical Activity and Sedentary } \\ \text { Behaviour Study }\end{array} \\ \text { METs } & \text { metabolic equivalents } \\ \text { MET.h/ } & \text { MET hours per week } \\ \text { week } & \\ \text { PAE } & \text { energy expenditure due to organised } \\ & \text { physical activity } \\ \text { SES } & \text { socio-economic status } \\ \text { sTNF- } \alpha \text { R1 } & \text { soluble TNF- } \alpha \text { receptor 1 }\end{array}$




\section{Introduction}

In adults the beneficial effect of regular physical activity on the traditional components of the metabolic syndrome is well documented. Recent studies indicate that physical activity is also inversely associated with low-grade inflammation [1], which is increasingly recognised as a significant feature of the metabolic syndrome and as an independent predictor of ischaemic events [2].

In children and adolescents, physical activity has similarly been found to be favourably associated with several metabolic syndrome features and with the risk of metabolic syndrome at a young adult age [3]. The more convincing studies concern insulin sensitivity [4-6] and dyslipidaemia [6], while the beneficial effects of physical activity on BP [6] have been demonstrated mainly for overweight children and adolescents with hypertension. As previously described for adults, an elevation of inflammatory markers, in particular Creactive protein (CRP) and IL-6, has been reported in obese adolescents [7, 8]. Two studies have examined the influence of physical activity on CRP in youths. While an inverse association between regular physical activity and CRP was observed in one [7], the other failed to show any effect of an 8-month physical training programme in obese adolescents [9]. The relationship of physical activity with IL-6 has never been studied in youths.

The mechanisms by which physical activity acts on the metabolic syndrome and low-grade inflammation are not entirely understood. Increasing data indicate that the improvement of insulin sensitivity is not totally explained by the influence of physical activity on body composition. It has been suggested, among other possibilities, that physical activity could target some of the cytokines expressed by adipose tissue, such as adiponectin, leptin or soluble TNF- $\alpha$ receptor 1 (sTNF- $\alpha \mathrm{R} 1)$, that are suspected to modulate insulin sensitivity and inflammatory processes $[2,10]$. In adults, the relationship of physical activity with the adipokines, which has been studied mainly after an acute exercise bout, remains unclear [11-14]. In youths, only the relationships with leptin have been examined. An inverse relationship of regular physical activity with leptin has been observed, independently of adiposity [15]. Changes in leptin have also been found to be related to changes in fitness induced by a training programme in obese adolescents [16].

The aim of this cross-sectional study was to investigate the associations between leisure-time physical activity, metabolic syndrome components and two inflammation surrogates (IL-6 and CRP) in adolescents participating in the Intervention Centred on Adolescents' Physical Activity and Sedentary Behaviour Study (ICAPS) [17]. Our hypothesis is that physical activity is favourably related to the metabolic syndrome and low-grade inflammation, independently of adiposity and fat localisation. We also wished to examine whether physical activity was associated with some adipocyte products (leptin, adiponectin and sTNF- $\alpha$ R1) and whether these contribute to the beneficial associations of physical activity with metabolic syndrome features.

\section{Subjects, materials and methods}

Population

ICAPS is an ongoing randomised intervention study, which began in 2002 and is aimed at encouraging physical activity to reduce weight gain and cardiovascular risk. The methodology of the study has been detailed elsewhere [17]. Briefly, 1,048 12-year-old adolescents from eight randomised public schools of the Department of the BasRhin were eligible to participate. In order to have a broad socio-economic context, randomisation was carried out after stratification on socio-geographical criteria. Ninetyone per cent of the eligible students participated in the study and 698 agreed to provide a blood sample. Due to some missing and non-fasting data, 640 subjects are considered in the present work. This study sample did not differ significantly from the total eligible population regarding BMI (18.8 vs $\left.18.9 \mathrm{~kg} / \mathrm{m}^{2}\right)$ and socio-economic status (SES), as evaluated from self-reported parents' occupational status. ICAPS has been reviewed and approved by the local Ethics Committee and the public schools' governing bodies. Consent to participate was obtained from all the children and their parents.

Clinical and anthropometric measurements

An initial physical and medical examination was conducted by trained professionals according to standardised methods. Height, weight, waist and hip circumferences were measured and the WHR was calculated. The percentage of body fat mass (BF) was evaluated by bioelectrical impedance (Tanita TBF-310; Tanita, Tokyo, Japan). BMI was calculated as the weight in kilograms divided by the height in metres squared. Overweight was defined according to the international sex-based percentiles that pass through a BMI value of $25 \mathrm{~kg} / \mathrm{m}^{2}$ at age 18 [18]. BP and heart rate were measured on seated children after a 5-min rest using a fully automatic BP monitor (Omron M4-I; Omron Healthcare, Milton Keynes, UK) and an adapted cuff size. Self-assessed Tanner stages [19] were obtained.

Physical activity

The adolescents' physical activity was assessed with the Modifiable Activity Questionnaire for Adolescents [20]. 
Participation in organised leisure-time physical activity (for competitive purpose or not) during the past year was reported by the students, who gave information on the weekly frequency, usual duration of each session and the number of months of practice. The intensities of the activities were derived from the 'Compendium of Physical Activity' [21] and expressed in metabolic equivalents (METs). The average weekly net energy expenditure due to organised physical activity (the five activities that were the most frequently performed were taken into account) was computed and expressed in MET hours per week (MET.h/week). As more than 30\% of the adolescents did not practise any organised physical activity, organised physical activity energy expenditure (PAE) was categorised into three classes: none, 0-15 MET.h/week and $\geq 15$ MET. h/week, with 15 MET.h/week corresponding to the median PAE of students practising at least one activity. The validity of the Modifiable Activity Questionnaire for Adolescents has been tested against the average of four 7-day recalls of activity and different measures of physical fitness in 100 randomly selected 15- to 18-year-old adolescents [20]. The results of this study provide evidence that the questionnaire yields a reasonable estimate of past-year physical activity with Spearman correlations between the questionnaire and the average of the three 7-day recalls ranging from 0.55 to 0.83 for different measures of physical activity, and a good 1-month test-retest reproducibility (intraclass correlation of 0.66). In our population, the reproducibility of the questionnaire, assessed on a sample of 79 12-year-old pupils with a 1-month test-retest interval, was also reasonably good with an intraclass correlation of 0.83 for organised physical activity.

Socio-economic data

Socio-economic data were obtained from the adolescents and from self-administered questionnaires completed by their parents. The highest occupational category of either parent was taken as an approximation of family SES. SES was categorised into three classes (low, middle and high) with a hierarchical classification of the occupational codes obtained from the French National Institute of Statistics and Economic Studies.

\section{Laboratory analysis}

Subjects were asked to fast for a minimum of $10 \mathrm{~h}$ before the blood sampling, which was performed in the morning before the medical examination with minimal venous stasis. All blood samples were processed within $3 \mathrm{~h}$ and the serum aliquoted for immediate analysis or long-term storage at $-80^{\circ} \mathrm{C}$ until assay (IL-6, sTNF- $\alpha$ R1, adiponectin and $\mathrm{CRP}$ ).
Plasma glucose concentrations were determined using a glucose oxidase method with intra- and interassay $\mathrm{CV}$ values of 1.8 and $3.0 \%$, respectively. Plasma HDL cholesterol was analysed with a cholesterol oxidase method (intra- and interassay CV values of 1.8 and $4.5 \%$, respectively) in the supernatant fraction after precipitation of non-HDL lipoproteins with magnesium-dextran precipitating reagent. Plasma triacylglycerols were determined using a standard glycerol blanked enzymatic triacylglycerol method (intra- and interassay CV values of 1.4 and $4.5 \%$, respectively). Plasma insulin was determined by chemiluminescence immunoassays performed on an Advia-Centaur automatic analyser (Bayer Diagnostics, Tarrytown, NY, USA) with intra- and interassay CV values of 4.5 and $6.5 \%$, respectively. CRP was measured by immunoassay using the Synchron-LX system (Beckman Coulter, Galway, Ireland) with intra- and interassay $\mathrm{CV}$ values of 5 and $7.5 \%$, respectively. IL-6, adiponectin and sTNF- $\alpha$ R1 were measured by ELISA (R\&D Systems, Minneapolis, MN, USA). The intra- and interassay $\mathrm{CV}$ values were, respectively, 2.8 and $4.5 \%$ for IL-6, 2.9 and $6.5 \%$ for adiponectin, and 4.4 and $6.1 \%$ for sTNF- $\alpha$ R1. Plasma leptin was measured by immunoradiometric assay using a commercial kit (Diagnostic Systems Laboratories, Webster, TX, USA). The intra- and interassay CV values were 3.7 and $5.1 \%$, respectively. Insulin resistance was estimated by the homeostasis model assessment (HOMA), calculated as (insulin $[\mu \mathrm{U} / \mathrm{ml}] \times$ glucose $[\mathrm{mmol} / \mathrm{l}]) / 22.5$ [22].

Metabolic syndrome

Since no standard definition exists for the metabolic syndrome in children or adolescents, subjects were classified as having a metabolic syndrome if they met three or more criteria of the NCEP III adult definition [23], as recently proposed by Cruz and Goran [24]. Cut-off points chosen to define the presence of one of the metabolic syndrome features were $>90$ th, $<5$ th and $>90$ th US percentiles for age and sex [25, 26], respectively, for triacylglycerol, HDL cholesterol and $\mathrm{BP},>1.1 \mathrm{~g} / \mathrm{l}$ for glucose and the 95th percentile of the British reference curves for waist circumference [27].

\section{Statistical analysis}

Data are presented as means $\pm \mathrm{SE}$ and interquartile range or as percentages.

General linear models were used to compare the metabolic syndrome features and adipocyte products according to weight and metabolic syndrome status and to PAE tertiles. Interaction factors were considered in order to evaluate a possible heterogeneity of the associations across levels of the other factors. Since no interaction was 
observed with sex, all the results are presented with boys and girls together. Due to the potential influence of sexual maturity on different metabolic syndrome features and that of SES on both overweight and physical activity practice, all the analyses were made with adjustment for sex, sexual maturity and SES. The relationships between PAE and the different variables were further analysed with (1) additional adjustment for BF and WHR, and (2) additional adjustment for adipokines. A logistic regression model was developed to study the relationship of PAE with the risk of metabolic syndrome with adjustment for sex, sexual maturity and SES. Log transformation was performed for variables with significant deviation from a normal distribution. This concerned insulin, HOMA, CRP, triacylglycerols and leptin. All statistical analyses were carried out using the SAS software (version 8; SAS Institute, Cary, NC, USA). Two-sided tests were used and significance was set at 0.05 .

\section{Results}

Characteristics of the subjects

The characteristics of participants are presented in Table 1. The subjects were $11.53 \pm 0.02$ years old with $22.7 \%$ of them being overweight. More than one-third of the adolescents did not practise any organised physical activity. On average, the adolescents spent $131 \mathrm{~min} /$ week in organised physical activity. Mean PAE was $11.91 \pm 0.56$ MET.h/week.

Table 1 Characteristics of the study population $(n=640)$

\begin{tabular}{lll}
\hline Variable & Means \pm SE & Interquartile range \\
\hline Age (years) & $11.53 \pm 0.02$ & $11.12-11.79$ \\
Boys (\%) & 49.22 & - \\
Weight $(\mathrm{kg})$ & $42.31 \pm 0.39$ & $35.45-47.45$ \\
Height $(\mathrm{cm})$ & $149.59 \pm 0.29$ & $145.00-155.00$ \\
BMI $\left(\mathrm{kg} / \mathrm{m}^{2}\right)$ & $18.78 \pm 0.14$ & $16.23-20.60$ \\
Overweight ${ }^{\mathrm{a}}(\%)$ & 22.66 & - \\
Tanner stage (\%) & & \\
1 & 26.25 & - \\
2 & 55.00 & - \\
3 & 18.75 & - \\
Organised physical & $131 \pm 6$ & $0-203$ \\
$\quad$ activity (min/week) & & - \\
Participation in organised & 65.78 & \\
$\quad$ physical activity (\%) & & $0-18.85$ \\
Organised physical activity & $11.91 \pm 0.56$ & \\
$\quad \begin{array}{l}\text { energy expenditure } \\
\text { (MET.h/week) }\end{array}$ & & \\
\hline
\end{tabular}

Values are least squares means $\pm \mathrm{SE}$ and interquartile range or percentages

${ }^{a}$ Overweight was defined according to the international sex-based centiles that pass through a BMI value of $25 \mathrm{~kg} / \mathrm{m}^{2}$ at age 18 [18]
Metabolic syndrome and adipocyte products

The clinical and biological characteristics of the participants are detailed in Table 2 with weight and metabolic syndrome specification and adjustment on sex, sexual maturity and SES. Metabolic syndrome was present in $5.8 \%$ of the entire sample, in $26.2 \%$ of the overweight, but in none of the normal-weight adolescents. Metabolic syndrome features, including insulin resistance as estimated by HOMA and inflammatory markers, were higher or more often encountered among the overweight without and with the metabolic syndrome compared with normal-weight subjects. These latter had also higher levels of adiponectin and lower levels of leptin and of sTNF- $\alpha$ R1. As expected, BF was unfavourably associated with all metabolic syndrome features $\left(p<10^{-4}\right)$ and also with adiponectin $(p=0.04)$, leptin $\left(p<10^{-4}\right)$ and sTNF- $\alpha$ R1 $\left(p<10^{-4}\right)$.

After adjustment for sex, sexual maturity, SES, BF and WHR, leptin was unfavourably associated with insulin $\left(p<10^{-4}\right)$, HOMA $\left(p<10^{-4}\right)$, triacylglycerols $\left(p<10^{-4}\right)$ and both IL-6 $\left(p=10^{-3}\right)$ and CRP $\left(p<10^{-2}\right)$. Adiponectin was favourably associated with insulin $\left(p<10^{-2}\right)$, HOMA $\left(p<10^{-2}\right)$, triacylglycerols $\left(p<10^{-3}\right)$ and HDL cholesterol $\left(p=10^{-4}\right)$, but none of the inflammatory markers. STNF- $\alpha$ R1 was related unfavourably to systolic BP $(p=0.02)$, insulin $(p=0.02)$, HOMA $(p=0.02)$, HDL cholesterol $(p=0.02)$, IL-6 $\left(p<10^{-4}\right)$ and CRP $\left(p<10^{-4}\right)$.

Physical activity, metabolic syndrome features and lowgrade inflammation

The levels of metabolic syndrome features and adipocyte products by PAE tertiles are presented in Table 3 with adjustment for sex, sexual maturity and SES. PAE was favourably associated with $\mathrm{BF}\left(p<10^{-2}\right)$, with nearly all metabolic syndrome features (except systolic BP and HDL cholesterol) and with IL-6 $\left(p<10^{-2}\right)$. As a consequence, the adolescents who did not practise organised physical activity tended to have a higher risk of metabolic syndrome as compared with the more active adolescents (odds ratio $=1.35$; 95\% CI: $0.56-3.26$ ). PAE was also inversely associated with leptin $\left(p<10^{-3}\right)$ but not with adiponectin or STNF- $\alpha$ R1.

Adiposity, adipokines and the relationships of physical activity with metabolic syndrome features

After further adjustment on BF and WHR, only the relationships of PAE with insulin levels, HOMA, IL-6 and leptin, but not with the other metabolic syndrome components, remained significant (Table 3). Adjusted least squares means \pm SE of HOMA (Fig. 1) from the lowest to the highest tertile of PAE were $1.99 \pm 0.07,1.80 \pm 0.07$ and 
Table 2 Clinical and biological characteristics of the study population with weight and metabolic syndrome status specification ${ }^{\mathrm{a}}$

\begin{tabular}{|c|c|c|c|c|}
\hline \multirow[t]{2}{*}{ Variable } & \multirow[t]{2}{*}{ Normal weight $(n=495)$} & \multicolumn{2}{|l|}{ Overweight } & \multirow[t]{2}{*}{$p$} \\
\hline & & Without metabolic syndrome $(n=107)$ & With metabolic syndrome $(n=38)$ & \\
\hline $\mathrm{BF}(\%)$ & $14.97 \pm 0.31$ & $27.21 \pm 0.60^{\mathrm{c}}$ & $30.38 \pm 1.02^{\mathrm{c}, \mathrm{d}}$ & $<10^{-4}$ \\
\hline Waist circumference $(\mathrm{cm})$ & $60.64 \pm 0.29$ & $73.77 \pm 0.59^{c}$ & $78.64 \pm 0.97^{\mathrm{c}, \mathrm{d}}$ & $<10^{-4}$ \\
\hline Systolic BP (mmHg) & $106.14 \pm 0.61$ & $111.02 \pm 1.22^{\mathrm{c}}$ & $118.26 \pm 2.06^{\mathrm{c}, \mathrm{d}}$ & $<10^{-4}$ \\
\hline Insulin $^{\mathrm{b}}(\mu \mathrm{U} / \mathrm{ml})$ & $6.94 \pm 0.21$ & $11.20 \pm 0.41^{\mathrm{c}}$ & $15.29 \pm 0.69^{\mathrm{c}, \mathrm{d}}$ & $<10^{-4}$ \\
\hline $\mathrm{HOMA}^{\mathrm{b}}$ & 1.570 .05 & $2.59 \pm 0.10^{\mathrm{c}}$ & $3.48 \pm 0.17^{\mathrm{c}, \mathrm{d}}$ & $<10^{-4}$ \\
\hline Triacylglycerols $^{\mathrm{b}}(\mathrm{g} / \mathrm{l})$ & $0.67 \pm 0.01$ & $0.78 \pm 0.03^{\mathrm{c}}$ & $1.23 \pm 0.05^{\mathrm{c}, \mathrm{d}}$ & $<10^{-4}$ \\
\hline HDL cholesterol (g/1) & $0.51 \pm 0.01$ & $0.45 \pm 0.01^{\mathrm{c}}$ & $0.34 \pm 0.02^{\mathrm{c}, \mathrm{d}}$ & $<10^{-4}$ \\
\hline IL-6 (pg/ml) & $0.69 \pm 0.04$ & $0.95 \pm 0.08^{\mathrm{c}}$ & $1.03 \pm 0.14^{\mathrm{c}}$ & $10^{-3}$ \\
\hline $\mathrm{CRP}^{\mathrm{b}}(\mathrm{mg} / \mathrm{l})$ & $0.57 \pm 0.06$ & $1.27 \pm 0.13^{\mathrm{c}}$ & $1.51 \pm 0.21^{\mathrm{c}}$ & $<10^{-4}$ \\
\hline Leptin $^{\mathrm{b}}(\mathrm{ng} / \mathrm{ml})$ & $10.09 \pm 0.53$ & $30.67 \pm 1.05^{\mathrm{c}}$ & $35.54 \pm 1.78^{\mathrm{c}}$ & $<10^{-4}$ \\
\hline Adiponectin (pg/ml) & $142.30 \pm 3.25$ & $128.72 \pm 6.38$ & $105.17 \pm 11.20^{\mathrm{c}}$ & $10^{-3}$ \\
\hline sTNF- $\alpha$ R1 (pg/ml) & $952.62 \pm 9.74$ & $1047.12 \pm 19.48^{\mathrm{c}}$ & $1074.75 \pm 32.64^{\mathrm{c}}$ & $<10^{-4}$ \\
\hline
\end{tabular}

Values are least squares means \pm SE adjusted for sex, sexual maturity and SES

${ }^{a}$ Overweight was defined according to the international sex-based centiles that pass through a BMI value of $25 \mathrm{~kg} / \mathrm{m}^{2}$ at age 18 [18]. Subjects were classified as having metabolic syndrome if they met three or more metabolic syndrome features (triacylglycerols, HDL cholesterol, BP, glucose and waist circumference). Comparisons were made by general linear models with adjustment for sex, sexual maturity and SES

${ }^{\mathrm{b}}$ Log-transformed variables were used to estimate the statistical significance. Least squares means $\pm \mathrm{SE}$ without log transformation are presented ${ }^{\mathrm{c}}$ Significantly different from normal-weight subjects

${ }^{\mathrm{d}}$ Significantly different from overweight subjects without metabolic syndrome

$1.78 \pm 0.07$ ( $p=0.04$ ). Adjusted means of IL-6 (Fig. 1) from the lowest to the highest tertile were $0.88 \pm 0.06,0.69 \pm 0.06$ and $0.70 \pm 0.06 \mathrm{pg} / \mathrm{ml}(p=0.02)$. Additional adjustment for the three adipocyte products did not affect the relationships of PAE with HOMA $(1.98 \pm 0.07,1.78 \pm 0.07$ and $1.78 \pm 0.07$ from the lowest to the highest tertile of PAE) and with IL-6 $(0.85 \pm 0.06,0.69 \pm 0.06$ and $0.69 \pm 0.06 \mathrm{pg} / \mathrm{ml}$ from the lowest to the highest tertile of PAE). The relationship between PAE and HOMA was still observed $(p=0.04)$ after further adjustment for IL-6.

\section{Discussion}

This cross-sectional study in adolescents demonstrates that regular physical activity is inversely associated with plasma

Table 3 Metabolic syndrome features and adipocyte products according to organised physical activity energy expenditure (PAE) tertiles

\begin{tabular}{|c|c|c|c|c|c|}
\hline \multirow[t]{2}{*}{ Variables } & \multicolumn{3}{|l|}{ PAE } & \multirow[t]{2}{*}{$p^{\mathrm{a}}$} & \multirow[t]{2}{*}{$p^{\mathrm{b}}$} \\
\hline & None $(n=219)$ & $0-15$ MET.h/week $(n=210)$ & $\geq 15$ MET.h/week $(n=211)$ & & \\
\hline $\mathrm{BF}(\%)$ & $18.63 \pm 0.60$ & $16.45 \pm 0.61$ & $16.69 \pm 0.61$ & $<10^{-2}$ & - \\
\hline Waist circumference $(\mathrm{cm})$ & $64.62 \pm 0.61$ & $62.51 \pm 0.63$ & $62.22 \pm 0.63$ & $<10^{-2}$ & - \\
\hline Systolic BP (mmHg) & $107.50 \pm 0.90$ & $106.71 \pm 0.92$ & $107.58 \pm 0.92$ & 0.72 & 0.72 \\
\hline Insulin $^{\mathrm{c}}(\mu \mathrm{U} / \mathrm{ml})$ & $8.82 \pm 0.34$ & $7.31 \pm 0.35$ & $7.40 \pm 0.35$ & $<10^{-2}$ & 0.05 \\
\hline $\mathrm{HOMA}^{\mathrm{c}}$ & $2.01 \pm 0.08$ & $1.66 \pm 0.08$ & $1.68 \pm 0.08$ & $10^{-2}$ & 0.04 \\
\hline Triacylglycerols ${ }^{\mathrm{c}}(\mathrm{g} / \mathrm{l})$ & $0.75 \pm 0.02$ & $0.69 \pm 0.02$ & $0.68 \pm 0.02$ & 0.03 & 0.22 \\
\hline HDL cholesterol (g/l) & $0.48 \pm 0.01$ & $0.50 \pm 0.01$ & $0.50 \pm 0.01$ & 0.07 & 0.28 \\
\hline IL-6 (pg/ml) & $0.88 \pm 0.06$ & $0.66 \pm 0.06$ & $0.68 \pm 0.06$ & $<10^{-2}$ & 0.02 \\
\hline $\mathrm{CRP}^{\mathrm{c}}(\mathrm{mg} / \mathrm{l})$ & $0.84 \pm 0.09$ & $0.63 \pm 0.09$ & $0.62 \pm 0.10$ & 0.11 & 0.43 \\
\hline $\operatorname{Leptin}^{\mathrm{c}}(\mathrm{ng} / \mathrm{ml})$ & $16.94 \pm 1.01$ & $12.76 \pm 1.03$ & $11.90 \pm 1.03$ & $<10^{-3}$ & $<10^{-2}$ \\
\hline Adiponectin (pg/ml) & $144.43 \pm 4.68$ & $140.12 \pm 4.73$ & $132.83 \pm 4.72$ & 0.17 & 0.09 \\
\hline sTNF- $\alpha$ R1 (pg/ml) & $983.44 \pm 14.18$ & $950.21 \pm 14.48$ & $975.39 \pm 14.49$ & 0.17 & 0.37 \\
\hline
\end{tabular}

Values are least squares means $\pm \mathrm{SE}^{a}$ adjusted for sex, sexual maturity and SES

General linear models were performed with PAE in tertiles

${ }^{a} p$ values for the differences between PAE tertiles with adjustment for sex, sexual maturity and SES

${ }^{\mathrm{b}} p$ values for the differences between PAE tertiles with further adjustment for BF and WHR

${ }^{c}$ Log-transformed variables have been used to estimate the statistical significance. Least squares means \pm SE without log transformation are presented 

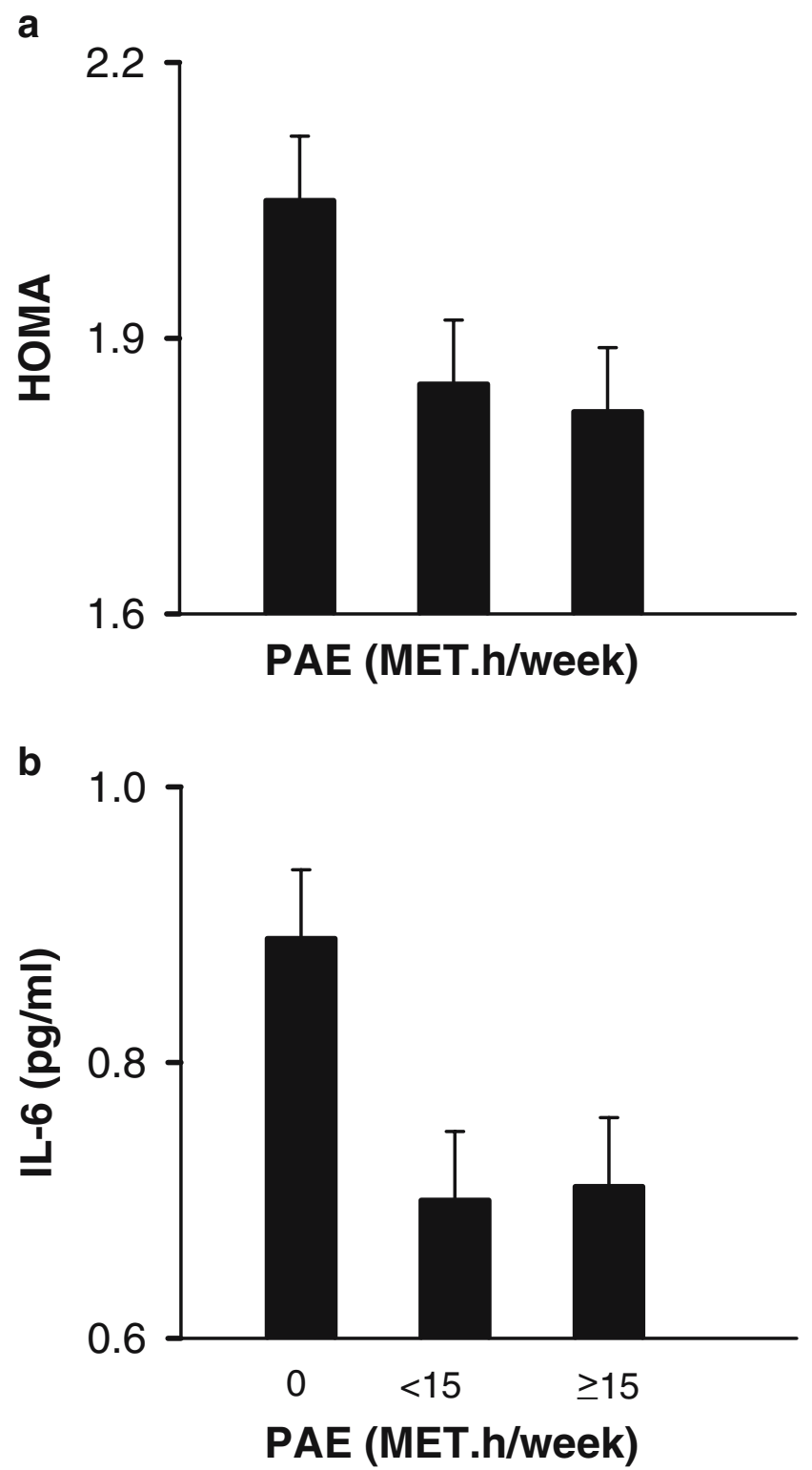

Fig. 1 Adjusted HOMA (a) and plasma IL-6 (b) (least squares means \pm SE) according to organised PAE tertiles in 12-year-old adolescents $(n=640)$. HOMA was adjusted for sex, sexual maturity, SES, BF and WHR. Comparisons were made by general linear models. Log-transformed variables were used to estimate the statistical significance. Global $p=0.04$ (a); $p=0.02$ (b)

insulin levels, insulin resistance and the proinflammatory cytokine IL-6 independently of adiposity and fat localisation. In contrast, the beneficial relationships of physical activity with the other metabolic syndrome features were explained by its association with BF. While these results are in line with other studies, the observed relationship between physical activity and IL-6 levels is novel in adolescents. Physical activity was also inversely associated with plasma leptin levels, independently of BF and WHR. However, our data indicate that the adipocyte products studied here (namely leptin, adiponectin and sTNF- $\alpha$ R1) do not substantially contribute to the beneficial relationships of physical activity with HOMA and IL-6.

Low physical activity has been related to increased fasting insulin levels or insulin resistance measured by HOMA in different observational studies in youths as previously described in adults. In one of the studies [28], changes in physical activity over a 6-year follow-up were inversely associated with changes in plasma insulin. The inverse relationship between physical activity and insulin resistance was confirmed in smaller studies using insulin clamps to measure insulin sensitivity more precisely [29] and in intervention studies focusing mostly on obese subjects $[5,6,29,30]$. As in most of these reports, the relationship of physical activity with insulin resistance was independent of adiposity and fat distribution. By contrast, we did not observe an independent association between physical activity and resting BP or plasma lipids. This is consistent with earlier studies showing a small effect of physical activity on BP in children with high-normal BP only [6]. Similarly, there are inconsistent data that physical activity has beneficial effects in youths on lipid levels, independently of adiposity [6].

$\mathrm{CRP}$ is an inflammatory marker synthesised by hepatocytes in response to IL-6, TNF- $\alpha$ and other cytokines. A convincing body of evidence has established low-grade inflammation as a strong independent risk factor for development of cardiovascular disease. Our results confirm reports [7, 8, 31] showing that CRP and IL-6 are increased in overweight adolescents and might represent, as for adults [2], an early component of the metabolic syndrome. Also, physical activity has been favourably related to different inflammation markers [1], including IL-6 and CRP, in adults [32]. The inverse association between physical activity and IL- 6 in the present study population indicates that such a beneficial relationship is observed as early as in adolescence. At variance with most studies, of which two were on children $[7,9]$, there was no association between physical activity and CRP levels. Other recent observational studies in adults could not demonstrate a significant independent association between physical activity and CRP $[33,34]$. The reason for these differences remains unclear. One possibility is that the association between physical activity and inflammation markers depends on the type and intensity of physical activity. Age or presence of metabolic abnormalities may be important. The low variability of CRP in our subjects may also have made a relationship with physical activity difficult to detect.

Several mechanisms might explain the favourable effect of physical activity on insulin sensitivity and inflammatory markers. One of these is the beneficial effect of physical activity on body weight and fatness. However, the beneficial association of physical activity remained signif- 
icant after controlling for adiposity. An enhancement of glucose transport in muscle cells and of the peripheral microcirculation has been proposed to explain the insulin sensitivity improvement. The inverse relationships of regular physical activity with IL-6, in apparent contradiction with the acute transient increase observed after exercise, may be due partly to the muscle production of natural cytokine inhibitors after each bout of exercise [13].

On the other hand, physical activity could also modulate adipocytokines. It is well established that adipocyte secretion products participate in the metabolic features associated with obesity. It has been suggested that leptin and $\mathrm{sTNF}-\alpha \mathrm{R} 1$ could reduce insulin sensitivity $[10,35,36]$. In addition to TNF- $\alpha$, which is a proinflammatory cytokine, leptin might also contribute indirectly to systemic inflammation [10]. Conversely, adiponectin is thought to improve insulin sensitivity and to have antiinflammatory properties [37]. Our study further indicates that these adipocytokines may mediate obesity-dependent effects of physical activity on the metabolic syndrome. However, the present results suggest that they do not directly account for the beneficial effects of physical activity on insulin resistance and IL-6 plasma levels. The absence of a relationship between physical activity and adiponectin levels is in agreement with intervention studies in which adiponectin was not affected by a training programme [38, 39]. An inverse relationship between physical activity and TNF- $\alpha$ or sTNF- $\alpha$ R1 has been reported but could require high-intensity activities [13]. The inverse relationship between physical activity and leptin observed here, as in a recent study in children [15], contrasts with the absence of leptin changes after endurance training or acute exercise when body composition is unaltered [39]. In any case, leptin was not a contributory factor to the effects of physical activity on the metabolic syndrome and inflammation in our population.

Our results highlighted that even low levels of organised physical activity were favourably associated with metabolic syndrome features and inflammatory markers. Although cross-sectional, these data suggest that physical activity levels achievable by most individuals may be beneficial for preventing metabolic features, which is important in a public health perspective. The median of the second PAE tertile was $8.3 \mathrm{MET}$.h/week, the equivalent of $70 \mathrm{~min}$ of recreational rollerblading or biking or of $1 \mathrm{~h}$ jogging per week. It should, however, be noted that physical activity considered here was organised practice, thus corresponding to activities characterised by at least moderate intensity (3-4 METs or more, e.g. dancing, table tennis or volleyball) and sessions generally lasting more than $30 \mathrm{~min}$. Consequently one cannot draw any conclusions about the health impact of similar levels of physical activity but of lower intensity or through shorter sessions.
Limitations of this study include its cross-sectional design, which does not permit a cause-and-effect association. Another weakness is that physical activity was selfreported, so that inaccuracies and recall bias cannot be ruled out. As no data are currently available in adolescents, the evaluation of the intensity of physical activity was based on the Compendium, established in adults, and thus may not be totally accurate. Although SES was taken into account, the influence of confounding behavioural or demographic variables, not taken into account here, cannot be ruled out. Finally, we used antibodies directed against the full-length adiponectin protein rather than the biologically active globular form, which may have masked true relationships with physical activity [40].

Due to the absence of a commonly accepted definition of the metabolic syndrome for children and adolescents, comparison of metabolic syndrome prevalence among studies is difficult. Nonetheless, the $6 \%$ prevalence found here is far lower than the about $10-12 \%$ prevalence reported in recent US and Canadian studies on adolescents [41]. These differences reflect higher obesity prevalence in North America but might also be partly due to physical activity differences among populations.

In summary, our study adds to the growing amount of data suggesting that regular physical activity is associated with improved insulin sensitivity and reduced systemic low-grade inflammation, independently of adiposity and fat localisation. Although an inverse relationship was also observed between physical activity and plasma leptin levels, the adipokines studied here do not explain the beneficial association of physical activity with the metabolic syndrome components. Altogether, these data further indicate that physical activity should be strongly encouraged in adolescents, not only for its effect on energy balance and body composition, but also for its preventive effect against cardiovascular risk factors.

Acknowledgements We thank the medical staff for their active participation, F. Goupilleau and the EA 3072 department (Louis Pasteur University of Strasbourg) for adipokine measurements and F. Ghazlane for her technical assistance. This study was supported by grants from Regime Local d'Assurance Maladie d'Alsace-Moselle (Regional Health Insurance of Alsace-Moselle), INSERM, Danone Institute and Fondation de la Recherche Médicale (Foundation for Medical Research).

\section{References}

1. Bassuk SS, Manson JE (2003) Physical activity and the prevention of cardiovascular disease. Curr Atheroscler Rep 5: 299-307

2. Devaraj S, Rosenson RS, Jialal I (2004) Metabolic syndrome: an appraisal of the pro-inflammatory and procoagulant status. Endocrinol Metab Clin North Am 33: 431-453 
3. van Mechelen W, Twisk JW, Post GB, Snel J, Kemper HC (2000) Physical activity of young people the Amsterdam Longitudinal Growth and Health Study. Med Sci Sports Exerc 32:1610-1616

4. Brage S, Wedderkopp N, Ekelund U et al (2004) Objectively measured physical activity correlates with indices of insulin resistance in Danish children. Int J Obes Relat Metab Disord 28:1503-1508

5. Ku CY, Gower BA, Hunter GR, Goran MI (2000) Racial differences in insulin secretion and sensitivity in prepubertal children: role of physical fitness and physical activity. Obes Res 8:506-515

6. Twisk JW (2000) Physical activity, physical fitness and cardiovascular health. In: Armstrong N, van Mechelen W (eds) Paediatric exercise and medicine. Oxford University Press, Oxford, pp 253-263

7. Cook DG, Mendall MA, Whincup PH et al (2000) C-reactive protein concentration in children: relationship to adiposity and other cardiovascular risk factors. Atherosclerosis 149:139-150

8. Weiss R, Dziura J, Burgert TS et al (2004) Obesity and the metabolic syndrome in children and adolescents. N Engl J Med 350:2362-2374

9. Barbeau P, Litaker MS, Woods KF et al (2002) Hemostatic and inflammatory markers in obese youths: effects of exercise and adiposity. J Pediatr 141:415-420

10. Kershaw EE, Flier JS (2004) Adipose tissue as an endocrine organ. J Clin Endocrinol Metab 89:2548-2556

11. Boudou P, Sobngwi E, Mauvais-Jarvis F, Vexiau P, Gautier JF (2003) Absence of exercise-induced variations in adiponectin levels despite decreased abdominal adiposity and improved insulin sensitivity in type 2 diabetic men. Eur J Endocrinol 149:421-424

12. Ferguson MA, White LJ, McCoy S, Kim HW, Petty T, Wilsey J (2004) Plasma adiponectin response to acute exercise in healthy subjects. Eur J Appl Physiol 91:324-329

13. Drenth JP, Krebbers RJ, Bijzet J, van der Meer JW (1998) Increased circulating cytokine receptors and ex vivo interleukin-1 receptor antagonist and interleukin-1beta production but decreased tumour necrosis factor-alpha production after a $5-\mathrm{km}$ run. Eur J Clin Invest 28:866-872

14. Hulver MW, Houmard JA (2003) Plasma leptin and exercise: recent findings. Sports Med 33:473-482

15. Romon M, Lafay L, Bresson JL et al (2004) Relationships between physical activity and plasma leptin levels in healthy children: the Fleurbaix-Laventie Ville Sante II Study. Int J Obes Relat Metab Disord 28:1227-1232

16. Barbeau P, Gutin B, Litaker MS et al (2003) Influence of physical training on plasma leptin in obese youths. Can J Appl Physiol 28:382-396

17. Simon C, Wagner A, Platat C et al (2006) ICAPS: a multilevel program to improve physical activity in adolescents. Diabetes Metab 32: 41-49

18. Cole TJ, Bellizzi MC, Flegal KM, Dietz WH (2000) Establishing a standard definition for child overweight and obesity worldwide: international survey. BMJ 320:1240-1243

19. Morris MM, Udry JR (1980) Validation of a self-administered instrument to assess stage of adolescent development. J Youth Adol 9:271-280

20. Aaron DJ, Kriska AM, Dearwater SR, Cauley JA, Metz KF, LaPorte RE (1995) Reproducibility and validity of an epidemiologic questionnaire to assess past year physical activity in adolescents. Am J Epidemiol 142:191-201

21. Ainsworth BE, Haskell WL, Leon AS et al (1993) Compendium of physical activities: classification of energy costs of human physical activities. Med Sci Sports Exerc 25:71-80

22. Gungor N, Saad R, Janosky J, Arslanian S (2004) Validation of surrogate estimates of insulin sensitivity and insulin secretion in children and adolescents. J Pediatr 144:47-55
23. No authors listed (2001) Executive summary of The Third Report of The National Cholesterol Education Program (NCEP) Expert Panel on Detection, Evaluation, and Treatment of High Blood Cholesterol in Adults. JAMA 285:2486-2497

24. Cruz ML, Goran MI (2004) The metabolic syndrome in children and adolescents. Curr Diab Rep 4:53-62

25. National Cholesterol Education Program. Report of the Expert Panel on Blood Cholesterol Levels in Children and Adolescents (1991). US Department of Health and Human Services, National Institutes of Health, National Heart, Lung, and Blood Institute, Bethesda, Maryland

26. National High Blood Pressure Education Program. Fourth Report on the Diagnosis, Evaluation, and Treatment of High Blood Pressure in Children and Adolescents (1996, revised 2005). US Department of Health and Human Services, National Institutes of Health, National Heart, Lung, and Blood Institute, Bethesda, Maryland

27. McCarthy HD, Jarrett KV, Crawley HF (2001) The development of waist circumference percentiles in British children aged 5.0 16.9 y. Eur J Clin Nutr 55:902-907

28. Raitakari OT, Taimela S, Porkka KV et al (1997) Associations between physical activity and risk factors for coronary heart disease: the Cardiovascular Risk in Young Finns Study. Med Sci Sports Exerc 29:1055-1061

29. Schmitz KH, Jacobs DR Jr, Hong CP, Steinberger J, Moran A, Sinaiko AR (2002) Association of physical activity with insulin sensitivity in children. Int J Obes Relat Metab Disord 26:1310-1316

30. Ramirez-Lopez G, Gonzalez-Villalpando C, Sanchez-Corona J et al (2001) Weight, physical activity, and smoking as determinants of insulinemia in adolescents. Arch Med Res 32:208-213

31. Visser M, Bouter LM, McQuillan GM, Wener MH, Harris TB (2001) Low-grade systemic inflammation in overweight children. Pediatrics 107:E13

32. Jankord R, Jemiolo B (2004) Influence of physical activity on serum IL-6 and IL-10 levels in healthy older men. Med Sci Sports Exerc 36:960-964

33. Rawson ES, Freedson PS, Osganian SK, Matthews CE, Reed G, Ockene IS (2003) Body mass index, but not physical activity, is associated with C-reactive protein. Med Sci Sports Exerc 35:1160-1166

34. Verdaet D, Dendale P, De Bacquer D, Delanghe J, Block P, De Backer G (2004) Association between leisure time physical activity and markers of chronic inflammation related to coronary heart disease. Atherosclerosis 176:303-310

35. Chu NF, Chang JB, Shieh SM (2003) Plasma leptin, fatty acids, and tumor necrosis factor-receptor and insulin resistance in children. Obes Res 11:532-540

36. Moreno LA, Pineda I, Rodriguez G et al (2002) Leptin and metabolic syndrome in obese and non-obese children. Horm Metab Res 34:394-399

37. Diez JJ, Iglesias P (2003) The role of the novel adipocyte-derived hormone adiponectin in human disease. Eur J Endocrinol 148:293-300

38. Hulver MW, Zheng D, Tanner CJ et al (2002) Adiponectin is not altered with exercise training despite enhanced insulin action. Am J Physiol Endocrinol Metab 283:E861-E865

39. Houmard JA, Cox JH, MacLean PS, Barakat HA (2000) Effect of short-term exercise training on leptin and insulin action. Metabolism 49:858-861

40. Lihn AS, Pedersen SB, Richelsen B (2005) Adiponectin: action, regulation and association to insulin sensitivity. Obes Rev 6:13-21

41. Cameron AJ, Shaw JE, Zimmet PZ (2004) The metabolic syndrome: prevalence in worldwide populations. Endocrinol Metab Clin North Am 33:351-375 